\title{
(2) OPEN ACCESS \\ Fifteen-minute consultation: Management of the infant born to a mother with toxoplasmosis in pregnancy
}

\author{
Anja Saso, ${ }^{1,2}$ Alasdair Bamford, ${ }^{3,4}$ Karen Grewal, ${ }^{5}$ Muna Noori, ${ }^{6}$ \\ James Hatcher, ${ }^{7}$ Felice D'Arco, ${ }^{8}$ Edward Guy, ${ }^{9}$ Hermione Lyall ${ }^{10}$
}

\begin{abstract}
- Additional material is published online only. To view please visit the journal online (http://dx.doi.org/10.1136/ archdischild-2018-316603).
\end{abstract}

For numbered affiliations see end of article.

\section{Correspondence to}

Dr Anja Saso, Academic Paediatrics, Imperial College London, London W2 1PY, UK; anja.saso@nhs.net

Received 26 January 2019 Revised 12 September 2019 Accepted 6 December 2019 Published Online First

18 February 2020

\section{Check for updates}

(C) Author(s) (or their employer(s)) 2020. Re-use permitted under CC BY-NC. No commercial re-use. See rights and permissions. Published by BMJ.

To cite: Saso A, Bamford A, Grewal K, et al. Arch Dis Child Educ Pract Ed 2020;105:262-269.

\begin{abstract}
Congenital toxoplasmosis occurs following transplacental transfer of Toxoplasma gondii. Irrespective of symptom status at birth, infants with congenital infection may develop serious long-term sequelae, including learning disability, seizures, hydrocephalus, motor and hearing deficits, chorioretinitis and retinal scarring with impaired vision. Timely diagnosis facilitates early initiation of therapy, aimed at prevention or amelioration of adverse clinical consequences. Diagnosis can be difficult, however, since acutely infected mothers are often asymptomatic and laboratory testing can be complex. Moreover, any decision to start treatment in the newborn must include careful consideration of the benefits and risks. This paper outlines a structured approach for managing an infant born to a woman with possible or confirmed T. gondii infection during pregnancy, including key aspects of the antenatal history, interpretation and timing of investigations, treatment and appropriate follow-up. Our recommendations are based on current evidence in the literature, consensus from two UK paediatric infectious disease centres and the UK specialist Toxoplasma Reference Unit.
\end{abstract}

\section{EPIDEMIOLOGY AND TRANSMISSION}

Congenital toxoplasmosis (CT) occurs when Toxoplasma gondii, an intracellular protozoan parasite, infects the fetus transplacentally. ${ }^{1}$ Worldwide, the estimated incidence of CT ranges from 0.1 to 6 cases per 1000 live births, with the highest burden in the Middle East and South America. ${ }^{2}$ However, the current systems for monitoring CT vary across different settings, precluding accurate estimates; in England and Wales, for example, there are no prenatal nor postnatal screening programmes, although enhanced surveillance reports approximately 7-10 confirmed cases annually (online supplementary table 1). ${ }^{3}$

T. gondii can be transmitted to humans by consumption of raw or poorly cooked meat containing viable tissue cysts, ingestion of water or food contaminated by oocysts excreted in cat faeces, vertical transmission of $T$. gondii during pregnancy, or by transplantation of tissues from an infected donor to an uninfected recipient. ${ }^{145}$ The risk of vertical transmission is dependent on gestational age at the time of primary maternal infection and may be reduced by antenatal treatment. For untreated women, the transmission rate is approximately $10 \%-15 \%$ in the first trimester rising to $70 \%-80 \%$ by the third trimester ${ }^{67}$; severity of outcome to the infant, however, is greatest if transmission occurs in the first trimester. $^{6} 8$ In immunocompromised women, CT may occur following reactivation of a previously latent infection. ${ }^{1}$

The differential diagnosis of CT mainly includes other congenital infections (eg, cytomegalovirus, rubella, syphilis, varicella) and conditions that cause retinal lesions and/or intracranial calcifications. ${ }^{15}$

\section{A SYSTEMATIC APPROACH TO MANAGEMENT}

In cases where maternal serology is suggestive of recent toxoplasmosis (eg, positive T. gondii-specific IgG and IgM results) and there is, therefore, a risk of CT, a systematic strategy should be adopted to evaluate the evidence for neonatal (and fetal) disease and, if appropriate, initiate treatment promptly. 
Box 1 Fetal ultrasound features suggestive of congenital toxoplasmosis

- Intracranial calcifications.

- Ventriculomegaly.

- Hydrocephalus.

- Ascites.

- Hepatosplenomegaly \pm intrahepatic calcifications.

- Severe intrauterine growth restriction.

- Echogenic bowel.

- Pericardial and/or pleural effusions.

- Hydrops fetalis.

- Polyhydramnios.

Note: These findings are non-specific and overlap with other intrauterine infections.

\section{Review of maternal background}

Antenatal history

Any symptoms or signs consistent with acute toxoplasmosis should be noted, including date of onset. Ten to twenty per cent of all individuals develop cervical lymphadenopathy or a 'flu-like' illness, which has a benign, self-limiting clinical course. ${ }^{16}$ Generally, however, T. gondii infection is asymptomatic and may go unnoticed. Immunosuppression is a risk factor for reactivation and/or more severe maternal infection and should also be identified. ${ }^{1}$

Antenatal investigations

Review of antenatal ultrasound and/or MRI findings is needed as there may be indications of evolving fetal toxoplasmosis, although these are non-specific (box 1). ${ }^{157}$

A positive T. gondii-specific IgM result during pregnancy suggests acute T. gondii infection, probably acquired after conception, and an associated risk of transplacental transmission. Previous maternal specimens, such as booking bloods, should be retrospectively tested; however, there are important caveats to interpretation, summarised in table $16^{6{ }^{9-11}}$ In equivocal cases, further testing should be undertaken either locally or at a national reference laboratory. ${ }^{6}$

T. gondii-specific IgG avidity can help discriminate between past and recently acquired infection; high avidity reliably excludes recent infection. Comparing serial blood results may demonstrate increasing antibody titres (IgM and/or IgG dye test) or confirm seroconversion during pregnancy (table 1). ${ }^{679-12}$ If infection acquired before conception can be confirmed, the risk to the pregnancy from T. gondii is considered low (in immunocompetent women), that is, T. gondii-specific

Table 1 Interpretation of common laboratory tests (maternal and infant) in suspected toxoplasmosis ${ }^{679-12}$

\begin{tabular}{|c|c|}
\hline Laboratory test & Significance \\
\hline $\begin{array}{l}\text { Screening test for } \\
\text { presence of } T \text {. gondii- } \\
\text { specific antibodies }\end{array}$ & $\begin{array}{l}\text { Often a latex agglutination or ELISA assay identifying combined (IgG and IgM) antibodies. } \\
\text { Usually performed at the local hospital laboratory. }\end{array}$ \\
\hline T.gondii-specific lgM & $\begin{array}{l}\text { First Ig to be detected: appears within 1-2 weeks of exposure. } \\
\text { May be difficult to interpret because: (A) can remain detectable beyond } 2 \text { years after infection in some highly sensitive assays; (B) false } \\
\text { positive rate as high as } 2 \% ;(C) \text { transplacental leakage of maternal T. gondii-specific IgM can lead to low positive T. gondii-specific IgM } \\
\text { in an uninfected infant shortly after birth (should disappear within } 1-2 \text { weeks); (D) only } 50 \%-60 \% \text { of congenitally infected babies } \\
\text { have detectable levels of } T \text {. gondii-specific IgM (and lgA) in the first month of life; levels may be undetectable even in severe disease, if } \\
\text { maternal seroconversion occurs early in pregnancy, or if treatment is given in pregnancy or at or soon after birth. } \\
\text { Consider congenital infection if } T \text {. gondii-specific lgM is present in infant and not in mother. }\end{array}$ \\
\hline T.gondii-specific $\lg \mathrm{A}$ & $\begin{array}{l}\text { IgA can cross the placenta (usually disappearing by } 2 \text { weeks of life), therefore: (A) passive transfer must be excluded; (B) only consider a } \\
\text { positive result significant if the mother is T. gondii-specific lgA negative. } \\
\text { May not be produced by congenitally infected infant in the first months of life. }\end{array}$ \\
\hline T.gondii-specific IgG & $\begin{array}{l}\text { Negative neonatal T. gondii-specific lgG essentially excludes congenital toxoplasmosis. } \\
\text { Appears from } 2 \text { weeks of primary infection and persists for life. } \\
\text { Maternal: seroconversion of IgM, IgG or IgA during pregnancy suggests recent acute maternal toxoplasma infection. } \\
\text { Neonatal: IgG crosses the placenta and therefore in the newborn may reflect past or current maternal infection. } \\
\text { Transplacental maternal T. gondii-specific IgG has a half-life of around 3-4 weeks. Persistence beyond } 12 \text { months of age is considered } \\
\text { confirmatory of congenital infection. }\end{array}$ \\
\hline $\begin{array}{l}\text { Sabin-Feldman dye } \\
\text { test }\end{array}$ & $\begin{array}{l}\text { Measures } T \text {. gondii-specific } \operatorname{lgM} \text { and lgG antibody. } \\
\text { Particularly helpful if: (A) initial dye tests are significantly raised or serial dye test results demonstrate increasing levels over time; (B) } \\
\text { infant dye test levels } \geq 4 \times \text { maternal levels are suggestive of congenital infection. }\end{array}$ \\
\hline Avidity test & $\begin{array}{l}\text { Measures functional affinity of } T \text {. gondii-specific lgG antibody. } \\
\text { Useful when } T \text {. gondii-specific lgM samples are equivocal: may help discriminate between past (especially preconception) and recently } \\
\text { acquired infection. } \\
\text { High avidity reliably excludes recent infection, but low avidity is not a reliable indicator of recent infection since rise in avidity may be } \\
\text { delayed in some individuals. }\end{array}$ \\
\hline T.gondii-specific NAAT & $\begin{array}{l}\text { Molecular diagnostic techniques, for example, PCR. } \\
\text { Can be done on amniotic fluid, blood or CSF samples. } \\
\text { Detection of } T \text {. gondii in amniotic fluid or infant specimens confirms congenital infection. }\end{array}$ \\
\hline
\end{tabular}

CSF, cerebrospinal fluid; Ig, immunoglobulin; NAAT, nucleic acid amplification test; PCR, Polymerase chain reaction; T.gondii, Toxoplasma gondii. 
Table 2 Clinical features in the neonate suggesting congenital toxoplasmosis ${ }^{145820}$

\begin{tabular}{|c|c|}
\hline Central nervous system disease & $\begin{array}{l}\text { Microcephaly } \\
\text { Hearing impairment } \\
\text { Seizures } \\
\text { Hydrocephalus } \\
\text { Motor deficits } \\
\text { Intracranial calcifications }\end{array}$ \\
\hline $\begin{array}{l}\text { Ophthalmological disease with } \\
\text { subsequent visual impairment }\end{array}$ & $\begin{array}{l}\text { Microphthalmia } \\
\text { Chorioretinitis (usually bilateral) } \\
\text { Retinal scarring } \\
\text { Strabismus } \\
\text { Nystagmus } \\
\text { Cataract }\end{array}$ \\
\hline Hepatic disease & $\begin{array}{l}\text { Hepatosplenomegaly } \\
\text { Jaundice }\end{array}$ \\
\hline Cardiorespiratory disease & $\begin{array}{l}\text { Pneumonitis } \\
\text { Myocarditis }\end{array}$ \\
\hline Systemic features & $\begin{array}{l}\text { Rash (may be 'blueberry-muffin') } \\
\text { Fever } \\
\text { Bone marrow suppression } \\
\text { (thrombocytopenia, anaemia) }\end{array}$ \\
\hline
\end{tabular}

IgG positive, IgM negative, with or without high IgG avidity on booking or preconception bloods.

Some women may be offered amniocentesis: a positive T. gondii nucleic acid amplification test (NAAT) result on amniotic fluid confirms intrauterine infection. ${ }^{9}{ }^{10}$ However, a negative result does not exclude fetal infection, particularly if maternal primary infection occurred in the third trimester. ${ }^{7}$

Treatment during pregnancy

Treatment given for acute toxoplasmosis in pregnancy should be recorded, including type and duration of therapy, since the interpretation of infant results may be affected. ${ }^{9}$ The two regimens often used are spiramycin (fetal prophylaxis preventing intrauterine infection) and combined pyrimethamine/sulfadiazine/ folinic acid (treatment of evolving fetal infection). ${ }^{13}$ Cases should be discussed with a fetal medicine expert and local infection specialist (microbiologist or infectious diseases physician). The efficacy of maternal treatment remains unclear and should not preclude treating the infant if appropriate. ${ }^{14}{ }^{15}$ However, observational studies have demonstrated effective reduction in transplacental transmission and/or severity of clinical manifestations in symptomatic infants ${ }^{1617}$; less is known about the impact on non-severe congenital sequelae.

\section{Assess clinical features in the newborn}

Table 2 identifies key clinical features suggestive of CT although no signs are pathognomonic. The classic triad is considered to be the presence of chorioretinitis, intracranial calcifications and hydrocephalus. ${ }^{45}$ However, up to $85 \%$ of congenitally infected newborns may have no findings on routine physical examination ${ }^{1}$; more specific testing, primarily examination of cerebrospinal fluid (CSF), neuroimaging and detailed ophthalmological review, is required to demonstrate subclinical end-organ abnormalities, as discussed below. ${ }^{18}$ One study demonstrated that up to $40 \%$ of infants with confirmed infection had retinal or central nervous system (CNS) abnormalities despite a normal routine initial neonatal examination. ${ }^{19}$

\section{Arrange urgent postnatal investigations \\ Blood tests}

A basic understanding of the significance of different infant tests is useful (table 1). Paired T. gondii-specific serology from the infant and the mother must be taken at birth (not cord blood). This enables a comparison between their T. gondii-specific IgM, IgA and IgG levels. Significantly raised levels of $T$. gondii-specific $\operatorname{IgM}$ or $\operatorname{IgG}$ (more than four times) in the infant compared with the mother are suggestive of congenital infection. ${ }^{9} 1018$ Detection of IgM in the neonate, however, should be interpreted with some caution, particularly where highly sensitive $\operatorname{IgM}$ tests are employed, since low levels of transplacental leakage can be detected. In such cases, these typically very low levels of maternal IgM disappear from the infant within 1-2 weeks. Detection of IgA in the newborn can also only be considered significant if the mother is IgA negative, since IgA readily crosses the placenta (disappearing by 2 weeks) and, therefore, passive transfer must be excluded (table 1)..$^{79}$

Conversely, only $50 \%-60 \%$ of congenitally infected infants will have positive T. gondii-specific IgM or IgA in the first month of life. Where results are negative, repeat testing should be carried out until at least 3 months of age, since seropositivity can be delayed. ${ }^{6}$ T. gondii-specific IgG testing should continue beyond this, for example, at 6 and 12 months. In uninfected infants, all maternally acquired IgG should have disappeared by 12 months (table 1). ${ }^{9}$ In infected infants treated before, at or soon after birth, a serological response may not occur until treatment is withdrawn. Thus, negative serological findings in such cases cannot exclude congenital infection, and follow-up testing is required after completion of treatment. ${ }^{11}$

Infant specimens found positive on T. gondii NAAT confirm congenital infection. Nevertheless, a blood NAAT may not detect organ-specific disease (including ocular toxoplasmosis). ${ }^{18}$

Additional useful blood tests include full blood count, liver function and renal profile. Tests to exclude other congenital infections should also be undertaken, particularly in equivocal cases.

\section{Lumbar puncture}

Any infant with findings consistent with CT should have a lumbar puncture and CSF sent for protein, glucose, cell count, culture and T. gondii NAAT. 

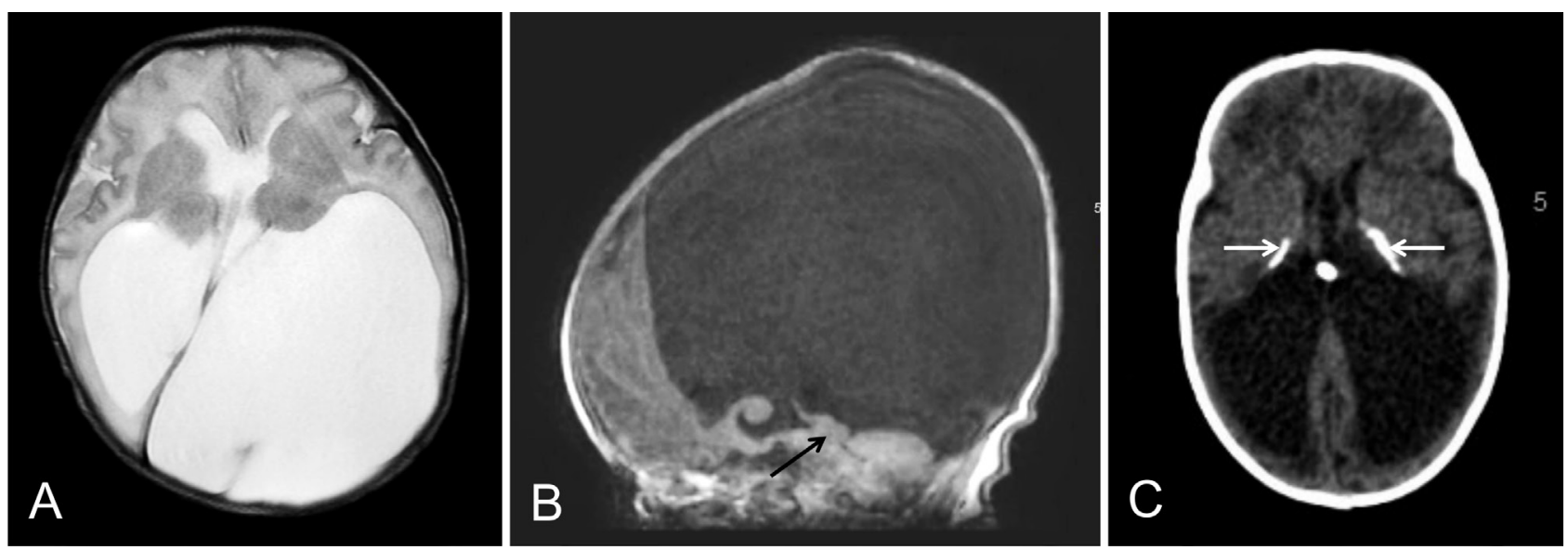

Figure 1 Axial T2 (A) and sagittal T1-weighted images (B) of a 1-day-old male newborn with congenital toxoplasmosis show marked hydrocephalus due to aqueduct stenosis (arrow in B) on a background of loss of cerebral white matter. Axial CT of an 11-week-old female infant with congenital toxoplasmosis $(C)$ demonstrates typical periventricular and basal ganglia calcifications (arrows) and dilatation of the ventricles, mainly due to loss of cerebral white matter ('ex-vacuo'), without radiological signs of acute obstructive hydrocephalus.

Neurological disease may manifest with mononuclear CSF pleocytosis or raised CSF protein. ${ }^{9} 1018$

\section{Neuroimaging}

In cases of suspected toxoplasmosis, cranial ultrasound and MRI brain should be arranged urgently, first to detect major structural abnormalities and thereafter to comprehensively describe $T$. gondii-related pathology, including intracranial calcifications, hydrocephalus, cortical atrophy and microcephaly (figure 1). Detailed MRI views of the globes can detect microphthalmia and of the aqueduct can ascertain the risk of developing hydrocephalus. ${ }^{4} 18$

\section{Arrange postnatal specialist reviews}

Ophthalmology

All newborns at risk of CT should be assessed urgently by an ophthalmologist. Ocular disease, such as chorioretinitis and scarring identified on specialist review, may be the only manifestation of CT, with no other visible clinical findings. ${ }^{15} 18$ Since these lesions can be delayed, developing later in childhood, repeat ophthalmological assessments should be considered beyond infancy to an age when the child is able to identify significant visual changes (and potentially lifelong). ${ }^{671112}$

Audiology

A hearing evaluation should be arranged, with follow-up testing if infection is confirmed.

\section{Treat infants with evidence of end-organ disease}

The definitive indication for starting therapy in an infant born to a mother with toxoplasmosis in pregnancy is evidence of end-organ disease, with or without confirmed serological or NAAT proof of infection in the neonate (table 3 ).

The underlying rationale is that newborns with untreated symptomatic CT have a significant risk of developing severe long-term complications, including intellectual, neurological, visual and hearing deficits. Untreated infants with subclinical infection can have similar outcomes, although the risk remains uncertain. 7111219

Data on comparative efficacy of different infant treatment options are limited and protocols are not standardised worldwide. ${ }^{713}$ The preferred regimen in the UK is a combination of sulfadiazine, pyrimethamine

Table 3 Evidence of congenital Toxoplasma gondii infection versus end-organ disease

\begin{tabular}{lll}
\hline Evidence of congenital infection & Evidence of end-organ disease \\
\hline Antenatal & Positive T. gondii NAAT on amniotic fluid. & Clinical features consistent with congenital toxoplasmosis on neonatal \\
Postnatal & Positive infant $T$. gondii-specific IgM and/or IgA beyond 2-3 & examination (table 2). \\
& weeks. & Typical abnormal findings on: \\
& Significantly raised levels of $T$. gondii-specific lgM or lgG & - Neuroimaging. \\
& $(\geq 4 \times$ titre) in the infant compared with the mother. & - Ophthalmology review. \\
& Increasing infant serial T. gondii-specific lgG titres or & - Audiology review. \\
& persistence beyond 12 months. & These findings may indicate subclinical end-organ damage. \\
& Positive $T$. gondii NAAT on infant specimens (including blood & - Positive $T$. gondii NAAT on infant CSF. \\
& and CSF).
\end{tabular}

CSF, cerebrospinal fluid; Ig, immunoglobulin;NAAT, nucleic acid amplification test; T.gondii, Toxplasma gondii. 


\section{Box 2 Suggested treatment regimen for}

\section{congenital toxoplasmosis ${ }^{5 *}$}

Pyrimethamine $1 \mathrm{mg} / \mathrm{kg}$ TWICE daily for 2 days.

- Then $1 \mathrm{mg} / \mathrm{kg}$ ONCE daily for 6 months.

- Then $1 \mathrm{mg} / \mathrm{kg}$ THREE times weekly to complete 12 months.

- Sulfadiazine $50 \mathrm{mg} / \mathrm{kg}$ TWICE daily for 12 months.

- Only start after neonatal jaundice resolved.

- Folinic acid (calcium folinate, Leucovorin) given to counteract bone marrow toxicity of pyrimethamine.

- 5-20 mg THREE times weekly during and for 1 week after pyrimethamine therapy.

- Dose adjusted to age $(5 \mathrm{mg}$ in neonates, $10 \mathrm{mg}$ in infants $>1$ month) and full blood count (table 3).

*As per the British National Formulary for Children (2019-2020) and Manual of Childhood Infections-The Blue Book, Fourth Edition (2016), endorsed by the Royal College of Paediatric and Child Health and European Society of Paediatric Infectious Diseases.

and folinic acid for 12 months (box 2), in keeping with recommendations made in many European countries, North America and Australia. ${ }^{671112}$ G6PD deficiency must be excluded prior to administration and steroids may be added for severe ocular disease or high CSF protein (more than $1 \mathrm{~g} / \mathrm{dL}$ ). ${ }^{118}$

There are no randomised controlled trials (RCT) of this combination therapy in infants. ${ }^{13}$ Previous large cohort studies, particularly in North America, have reported that a 12-month therapeutic course is associated with significantly decreased incidence and severity of long-term sequelae and new-onset ocular disease when compared with untreated historical controls or those treated for a shorter duration. ${ }^{8} 1920$ In European studies, treatment was often started antenatally precluding reliable determination of the effects of postnatal therapy. Data predominantly demonstrated an improvement in ocular prognosis following early diagnosis and timely initiation of treatment. ${ }^{11} 13$ A French RCT is currently comparing the efficacy of triple therapy for 3 vs 12 months on the development of chorioretinitis over a 2-year period in infants with non-severe CT (ClinicalTrials.gov NCT01202500).

Despite better outcomes, treated infants are still at risk of developing delayed complications. ${ }^{8}$ This is because current treatment targets T. gondii tachyzoites (rapidly proliferating developmental stage) but does not successfully eliminate slower-growing, latent bradyzoites established within tissue cysts, particularly in the eye and CNS. ${ }^{1518}$ Therefore, relapse of ocular (including late-onset retinal lesions) and CNS disease can occur, in some cases even several years after treatment has been completed, potentially requiring retreatment. ${ }^{11} 18$

\section{Monitor infants with no evidence of end-organ disease}

Given the paucity of available evidence, there is no clear consensus on the benefit of treating neonates who have been born to a mother with toxoplasmosis in pregnancy and who are asymptomatic without confirmed end-organ disease. ${ }^{711-13}$ Positive fetal or infant serology or NAAT results, although not indications for treatment, are still useful to diagnose $T$. gondii-specific infection in the infant (table 3 ) and, therefore, guide longer term follow-up (figure 2).

Most infectious disease paediatricians in the UK would monitor serology and defer treatment, bearing in mind the toxicity of treatment. Close outpatient follow-up is required, only starting treatment if clinically indicated. This decision may vary in other settings.

Figure 2 summarises the step-by-step considerations in the investigation and management of newborns at risk of CT. Interpretation of results and decisions about treatment should be made in conjunction with microbiologists and infectious disease specialists. Families should be fully informed about the risks and benefits of treatment, including limitations of current knowledge and diagnostic tests.

\section{Follow-up of treated infants}

Close monitoring of infants on treatment for adverse events, disease recurrence, symptom progression and therapeutic response is critical (table 4). ${ }^{711} 12$ Follow-up is recommended in a specialist paediatric infectious diseases clinic. Potential prognostic factors associated with poor outcomes include delay in initiation of treatment (and/or correction of hydrocephalus); prolonged hypoxia or episodes of hypothermia, apnoea and bradycardia at presentation; CSF protein more than $1 \mathrm{~g} / \mathrm{dL}$ and cerebral atrophy. ${ }^{8}$

Parents should be offered peer support through networking groups and access to helpful online resources. The UK Tommy's charity provides online support and comprehensive information for parents (https://www.tommys.org/pregnancy-information/ pregnancy-complications/infections-pregnancy/ toxoplasmosis-pregnancy).

\section{CONCLUSION}

When faced with a case of suspected CT, the paediatric team must be aware of the workup required to confirm diagnosis, the significance of the results obtained and the importance of timely treatment to prevent or ameliorate adverse clinical consequences. The key learning points are:

- Positive T. gondii-specific IgM and IgG in pregnancy does not necessarily equate to subsequent congenital toxoplasmosis and further investigation and monitoring of the infant (and fetus) are required.

- A thorough postnatal examination is key, although the majority of infected newborns are asymptomatic on initial assessment but may still develop serious long-term sequelae; ophthalmology review and neuroimaging are necessary to detect subclinical end-organ abnormalities.

- T. gondii NAATs and serial infant T. gondii-specific serology are helpful to diagnose infection, although 


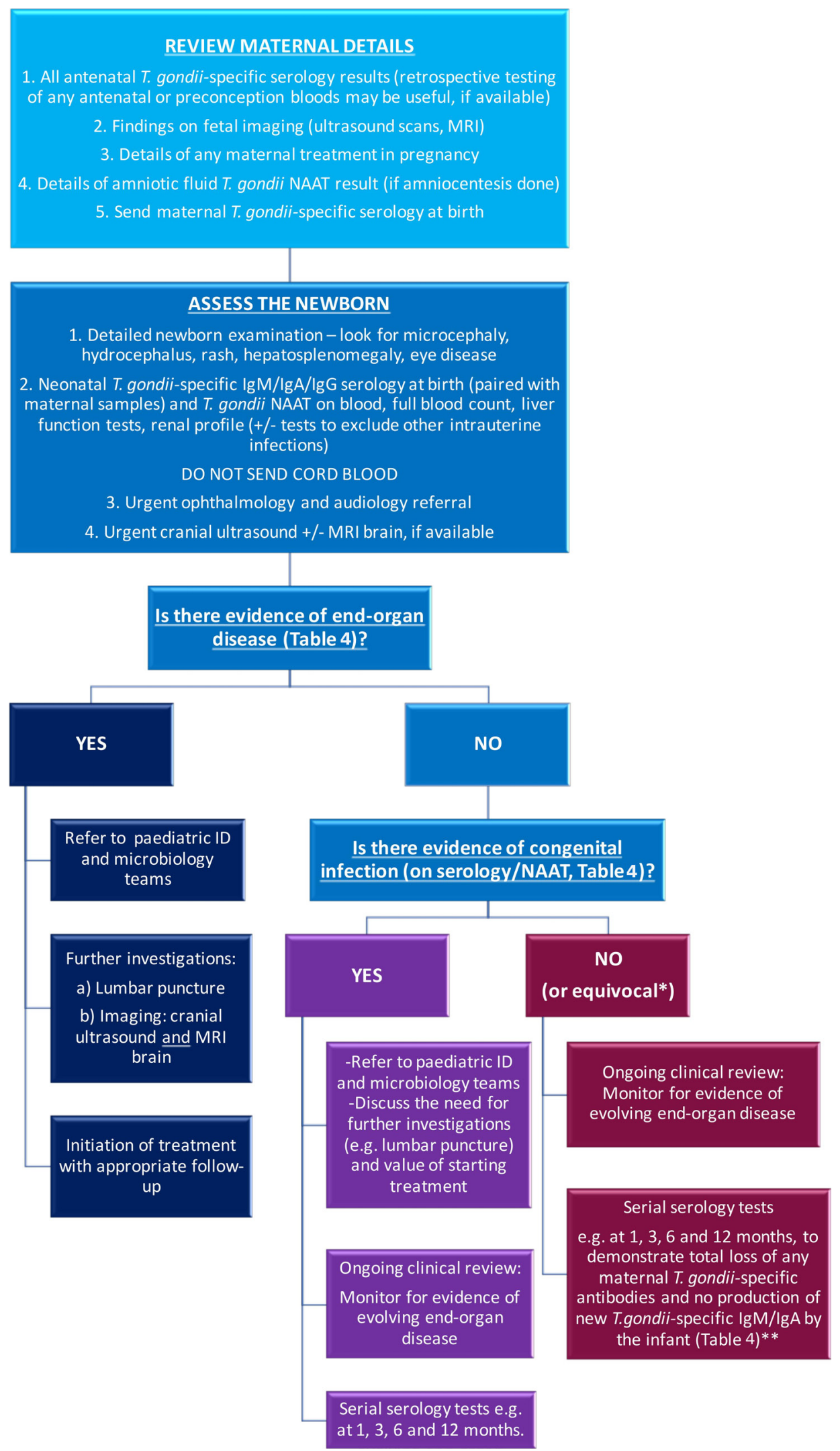

Figure 2 Quick reference guide for paediatricians on the management of neonates born to mothers with suspected or confirmed toxoplasmosis in pregnancy (ie, positive Toxoplasma gondii-specific lgM and lgG serology results). *Equivocal serology results include: isolated positive T. gondiispecific $\lg G$ and/or IgM and/or IgA results at birth. ${ }^{* *}$ If there is no evidence of evolving end-organ disease, the infant can be discharged from follow-up as soon as all maternal T. gondii-specific antibody is lost, and there is no evidence of new production of $T$. gondii-specific antibody by the infant. T.gondii, Toxoplasma gondii; ID, infectious diseases; Ig, immunoglobulin; NAAT, nucleic acid amplification test; MRI, magnetic resonance imaging. 
Table 4 Assessment of medication toxicity, response to therapy and disease progression in infants treated for congenital toxoplasmosis

\begin{tabular}{|c|c|}
\hline ty & $\begin{array}{l}\text { Full blood count to be done at baseline then during treatment to look for drug-induced neutropenia, aplastic anaemia and haemolysis (if } \\
\text { co-existing G6PD deficiency). } \\
\text { - Suggested timing is once weekly when on daily pyrimethamine then monthly if stable. } \\
\text { - Withhold treatment if absolute neutrophil count }<0.5 \times 10^{\wedge} 9 / \mathrm{L} \text {, but continue folinic acid ( } \pm \text { consider increasing dose up to } 20 \mathrm{mg} \text { ). } \\
\text { Liver function tests and renal profile to be done at baseline then monthly if stable. }\end{array}$ \\
\hline $\begin{array}{l}\text { Response to } \\
\text { therapy }\end{array}$ & $\begin{array}{l}\text { Interval serology testing: } T \text {. gondii-specific } \lg G \text { and IgM every } 3 \text { months until therapy is completed then at the end of treatment and at 1, } 3 \\
\text { and } 6 \text { months off treatment. } \\
\text { Rebound rise in } T \text {. gondii-specific IgM } \pm \text { IgG levels may be seen following treatment; this does not necessarily indicate relapse but more likely } \\
\text { reflects a delayed serological response to infection. }\end{array}$ \\
\hline $\begin{array}{l}\text { Disease progression } \\
\text { and recurrence }\end{array}$ & $\begin{array}{l}\text { Follow-up with paediatric infectious disease specialist team. } \\
\text { Measurement of head circumference at each outpatient visit. } \\
\text { Regular ophthalmology and vision assessments throughout treatment and at 3,6 and } 12 \text { months following completion, then at least } \\
\text { annually for life (to identify potential late-onset complications). } \\
\text { Consider neurodevelopmental, neurological and auditory review. } \\
\text { Inform parents about the risks of development of seizures and/or raised intracranial pressure: ensure they have an emergency action pla } \\
\text { Urgently repeat brain imaging if there are any signs/symptoms of raised intracranial pressure. }\end{array}$ \\
\hline
\end{tabular}

Suggested time points only.

Ig, immunoglobulin; T.gondii, Toxoplasma gondii.

there are important caveats to the interpretation of laboratory results.

- Treatment is indicated if there is evidence of end-organ disease.

- End-organ damage, particularly ocular lesions, can present beyond the neonatal period and, therefore, suspected cases must be followed up appropriately.

- Multidisciplinary care is recommended with clear communication encouraged between obstetric, fetal medicine, midwifery, neonatal, laboratory, specialist infectious disease services and parents.

\section{Remaining challenges and future aims}

- To accurately characterise the burden of congenital toxoplasmosis worldwide.

- Ongoing review of the potential for prenatal and/or postnatal screening programme in different settings.

- To develop novel medications that are curative and/or vaccinations for prevention of disease.

- To establish a global consensus on type, dosing and duration of treatment.

- To assess the efficacy of treating infected infants with no evidence of end-organ disease or those with equivocal results, including impact on late-onset ocular lesions in childhood/adolescence.

- To formally assess the effectiveness of different strategies for Toxoplasma gondii risk reduction around the time of conception and during pregnancy (eg, education on behaviour modification, food safety practices).

\section{Author affiliations}

'Department of Academic Paediatrics, Imperial College London, London, UK ${ }^{2}$ Vaccines \& Immunity Theme, MRC The Gambia at London School of Hygiene and Tropical Medicine, Banjul, Gambia

${ }^{3}$ Department of Paediatric Infectious Diseases, Great Ormond Street Hospital for Children NHS Foundation Trust, London, UK

${ }^{4}$ Section of Infection, Inflammation and Rheumatology, UCL Great Ormond Street Institute of Child Health, London, UK

${ }^{5}$ Tommy's National Centre for Miscarriage Research, Imperial College London, London, UK
${ }^{6}$ Department of Women and Children, Queen Charlotte's and Chelsea Hospital, Imperial College Healthcare NHS Trust, London, UK

${ }^{7}$ Department of Microbiology, Laboratory Medicine, Great Ormond Street Hospital for Children NHS Trust, London, United Kingdom

${ }^{8}$ Department of Paediatric Neuroradiology, Great Ormond Street Hospital for Children NHS Foundation Trust, London, UK

${ }^{9}$ Toxoplasma Reference Unit, Public Health Wales, Swansea, UK

${ }^{10}$ Department of Paediatric Infectious Diseases, St Mary's Hospital, Imperial

College Healthcare NHS Trust, London, UK

Acknowledgements AS acknowledges funding from the Wellcome Trust Institutional Strategic Support Fund Global Health Fellowship, award number 204834/Z/16/Z.

Contributors AS conducted the literature review and wrote the first draft. $\mathrm{KG}$ and $\mathrm{MN}$ contributed specialist obstetrics and fetal medicine advice. $\mathrm{JH}$ contributed specialist microbiology advice. FDA contributed specialist neuroradiology advice and provided Figure 1. EG, AB and HL made expert recommendations for the management of infants at risk of congenital toxoplasmosis. All authors reviewed the content and suggested amendments that AS incorporated. All authors approved the final version.

Competing interests None declared.

Patient consent for publication Not required.

Provenance and peer review Commissioned; externally peer reviewed.

Data availability statement All data relevant to the study are included in the article or uploaded as supplementary information.

Open access This is an open access article distributed in accordance with the Creative Commons Attribution Non Commercial (CC BY-NC 4.0) license, which permits others to distribute, remix, adapt, build upon this work noncommercially, and license their derivative works on different terms, provided the original work is properly cited, appropriate credit is given, any changes made indicated, and the use is non-commercial. See: http://creativecommons.org/ licenses/by-nc/4.0/.

\section{REFERENCES}

1 Montoya JG, Liesenfeld O, Toxoplasmosis LO. Toxoplasmosis. The Lancet 2004;363:1965-76.

2 Torgerson PR, Mastroiacovo P. The global burden of congenital toxoplasmosis: a systematic review. Bull World Health Organ 2013;91:501-8.

3 Halsby K, Guy E, Said B, et al. Enhanced surveillance for toxoplasmosis in England and Wales, 2008-2012. Epidemiol Infect 2014;142:1653-60. 
4 McAuley JB, Toxoplasmosis C. Congenital toxoplasmosis. J Pediatric Infect Dis Soc 2014;3:S30-5.

5 Christopher B, Wilson MD, Victor Nizet MD, et al. Toxoplasmosis. 8th edn. Philadelphia: Elsevier Saunders, 2016.

6 Division PHWHP. Public Health Wales Health Protection Division - Toxoplasma Reference Unit. Available: http:// www.wales.nhs.uk/sites3/page.cfm?orgId $=457 \&$ pid $=25359$ [Accessed 18 Nov 2018].

7 Maldonado YA, Read JS. Committee on infectious diseases. diagnosis, treatment, and prevention of congenital toxoplasmosis in the United States. Pediatrics 2017;139:e20163860.

8 McAuley J, Boyer KM, Patel D, et al. Early and longitudinal evaluations of treated infants and children and untreated historical patients with congenital toxoplasmosis: the Chicago Collaborative treatment trial. Clinical Infectious Diseases 1994;18:38-72 http://www.ncbi.nlm.nih.gov/pubmed/ 8054436

9 Pomares C, Montoya JG. Laboratory diagnosis of congenital toxoplasmosis. J Clin Microbiol 2016;54:2448-54.

10 Murat J-B, Fricker Hidalgo H, Brenier-Pinchart M-P, et al. Human toxoplasmosis: which biological diagnostic tests are best suited to which clinical situations? Expert Rev Anti Infect Ther 2013;11:943-56.

11 Peyron F, L'ollivier C, Mandelbrot L, et al. Maternal and congenital toxoplasmosis: diagnosis and treatment recommendations of a French multidisciplinary Working group. Pathogens 2019;8:24.
12 Paquet C, Yudin MH, No YMH. No. 285-Toxoplasmosis in pregnancy: prevention, screening, and treatment. J Obstet Gynaecol Can 2018;40:e687-93.

13 Robert-Gangneux F. It is not only the cat that did it: how to prevent and treat congenital toxoplasmosis. J Infect 2014;68 Suppl 1:S125-33.

14 Peyron F, Wallon M, Liou C, et al. Treatments for toxoplasmosis in pregnancy. Cochrane Database Syst Rev 2009;1999:CD001684.

15 Thiébaut R, Leproust S, Chêne G, et al. Effectiveness of prenatal treatment for congenital toxoplasmosis: a metaanalysis of individual patients' data. Lancet 2007;369:115-22.

16 Cortina-Borja M, Tan HK, Wallon M, et al. Prenatal treatment for serious neurological sequelae of congenital toxoplasmosis: an observational prospective cohort study. PLoS Med 2010;7:e1000351.

17 Hotop A, Hlobil H, Gross U. Efficacy of rapid treatment initiation following primary Toxoplasma gondii infection during pregnancy. Clin Infect Dis 2012;54:1545-52.

18 Khan K, Khan W. Congenital toxoplasmosis: an overview of the neurological and ocular manifestations. Parasitol Int 2018;67:715-21.

19 Guerina NG, Hsu HW, Meissner HC, et al. Neonatal serologic screening and early treatment for congenital Toxoplasma gondii infection. the new England regional Toxoplasma Working group. N Engl J Med 1994;330:1858-63.

20 McLeod R, Boyer K, Karrison T, et al. Outcome of treatment for congenital toxoplasmosis, 1981-2004: the National collaborative Chicago-Based, congenital toxoplasmosis study. Clin Infect Dis 2006;42:1383-94. 